\title{
EL PARADIGMA DEL HIPERCONSUMO EN CONTEXTOS ESPACIALES AMBIENTALMENTE CRÍTICOS. SANTA FE (ARGENTINA) \\ Y LA URBANIZACIÓN DEL VALLE ALUVIAL DEL RÍO PARANA \\ A FINALES DEL SIGLO $\mathbf{X X}$
}

\section{Gisela Ariana Rausch}

Arquitecta graduada de la Facultad de Arquitectura, Diseño y Urbanismo de la Universidad Nacional del Litoral. Doctora en Humanidades y Artes, mención Historia por la Universidad Nacional de Rosario. Docente ordinaria por Concurso Nacional en la asignatura Teorías y Producción arquitectónica en el siglo XX, e investigadora en el Instituto de Teoría e Historia Urbano Arquitectónica (INTHUAR) de la Universidad Nacional del Litoral. Entre 2007 y 2010, becaria de la Agencia Nacional de Promoción Científica y Técnica (ANPCyT) en el marco del Proyecto Observatorio Urbanístico del Área Metropolitana Santa Fe-Paraná. De 2010 a 2012, becaria doctoral del CONICET. Desde 2012 becaria posdoctoral del CONICET. Seleccionada en 2012 para ingresar en la Carrera de Investigador Científico (CIC) en el CONICET.

ISNN 1666-6I86. Volumen 16 N. ${ }^{\circ} 16$ (Junio de 2014) Pp. 087-I06 - Recibido: 23-07-I3.Aceptado: 0I-03-14 
$\underline{\text { Resumen }}$

La segunda mitad del siglo XX - y principalmente las dos últimas décadas - ha visto surgir en muchas ciudades occidentales un modelo territorial que constituyó un salto cualitativo respecto del modo anterior de configuración espacial. La aparición de las nuevas periferias urbanas devino de un proceso en estrecha relación con el régimen de acumulación correspondiente a la actual fase del capitalismo (que se ha dado en llamar posfordista), siendo extensa y amplia la bibliografía sobre dicha problemática.

Aquí se intenta, a partir del análisis de un caso en una ciudad intermedia de Argentina, dar cuenta del modo específico en que tal modelo de hiperconsumo ha podido cristalizar en espacios críticos ambientalmente, emergiendo así un modo de ocupación territorial que contradice las mismas premisas del modelo original.

\section{Palabras clave}

Suburbanización, enclaves urbanos, excepción legal, riesgo hídrico.

\section{Abstract}

The second half of the XX century - mainly during its last two decades - has seen, in many western cities the emergence of a territorial model which signified a qualitative leap with respect to the previous model of urban spatial configuration. The appearance of the new urban peripheries resulted from a process closely linked to forms of accumulation emerging from capitalism's current, post-fordist phase. This process has been abundantly covered by recent bibliography. On the basis of the analysis of a medium sized city in Argentina, this paper attempts to show the specific way that the hyper consumptive model has crystallized in environmentally critical spaces, from which has emerged a form of occupation of territory which contradicts the premises of the original model of private neighborhood growth..

\section{Keywords}

Suburbanization, urban settlements, legal exception, hydrological risk. 
El paradigma del hiperconsumo en contextos espaciales ambientalmente críticos. Santa Fe (Argentina) y la urbanización del valle aluvial del río Paraná a finales del siglo xx

\section{INTRODUCCIÓN}

Como lo demuestra la amplia bibliografía sobre estudios urbanos surgida en las dos últimas décadas del siglo XX, la ocupación suburbana no es un fenómeno propiamente de los últimos tiempos. La casa de fin de semana en las periferias de las ciudades es un fenómeno que puede rastrearse ya en el siglo XIX en algunas ciudades europeas, ${ }^{1}$ y la disciplina urbanística ha realizado varios intentos de urbanizaciones periféricas, como los proyectos utópicos, las ciudades fábrica y las ciudades que PAOLO Sica llamó "del tiempo libre" (SICA, 1981). Más tarde, a principios del siglo XX, aparecerían las garden cities, ${ }^{2}$ que constituirán reformulaciones de las últimas.

En Argentina, siguiendo el modelo británico, buena parte de la elite porteña adoptó a finales del siglo XIX la costumbre de la casa de campo extraurbana. Esta costumbre se vinculaba con los valores (europeizados) que circulaban en la alta sociedad porteña, pero también con las epidemias de fiebre amarilla, que en la segunda mitad del siglo XIX habían asolado la ciudad, siendo motivo de la búsqueda de espacios considerados saludables. ${ }^{3}$ En ese entonces, llegar a los espacios periféricos de la ciudad requería la existencia del ferrocarril, y fue así que a partir del trazado de rieles se consolidaron núcleos urbanos con tales características. ${ }^{4}$

Desde la segunda década del siglo XX, junto al desarrollo de la industria automotriz en forma masiva y de las infraestructuras viales, comenzó a darse en Norteamérica un importante movimiento de los sectores sociales medios hacia el extrarradio urbano, conformando así las denominadas periferias urbanas (HALL, 1996: 286-330). Estas periferias del siglo XX, además de responder a procesos históricos diferentes de los que se habían desarrollado en la primera mitad del siglo en Europa, contenían tanto elementos diferenciales del modelo europeo, como una morfología específica ${ }^{5}$. Dispersión espacial, vivienda unifamiliar y homogeneidad edilicia organizadas en enclaves urbanos constituyeron un patrón de ocupación que se difundió ampliamente en las décadas subsiguientes. Dicho patrón fue tomando matices particulares en estrecha relación con las condiciones histórico-geográficas del lugar de implantación, pero estrechamente vinculado con lo que podría denominarse el modelo del hiperconsumo.

La noción de hiperconsumo (o consumismo) ha sido trabajada por autores como ZYGMUNT BAUMAN (2007) y Gilles Lipovetsky (2007; 2008). BAUMAN considera que la última fase del capitalismo se corresponde con un pasaje del consumo al consumismo, que estaría dado por una modificación sustancial en las relaciones entre objeto y sujeto. Así, del consumo
1- Se hace referencia a la denominada casa de campo, inspirada en el modelo victoriano.

2- Sobre el tema puede verse MUMFORD, 1966; vol. 2; BENEVOLO, 1967: GRAVAGNUOLO 1998; SICA, 1981

3- Puede verse: SICA, 1981 Cap. XII y BALLENT, 1998 : 88-101.

4- En Buenos Aires, el Tortugas en 1930 y el Highland Park en 1940 fueron las primeras urbanizaciones cerradas.

5- La bibliografía sobre este tema es amplia y con diversos matices que en general se corresponden con los intereses disciplinares desde los cuales se analiza el fenómeno. Algunos autores son: INDOVINA, 1990; MONCLÚS, 1998; ASCHER, 1995. En el ámbito nacional desde la Sociología el trabajo más difundido es el de SVAMPA, 2001 y 2004; en Geografía Diego Ríos ha analizado el caso del Tigre (Buenos Aires), la antropóloga MARÍA CARMAN (2011) ha trabajado la relación entre periferias y naturaleza, por mencionar solo algunos. 
6- La Guardia y Alto Verde responden a procesos diferentes de urbanización. entendido como parte de la supervivencia biológica humana se ha pasado al consumismo, en el cual el primero ha devenido en una fuerza integradora, estratificadora y constituyente del sujeto. En estos términos, el consumo pasa a ser un acuerdo social.

Por su parte, LIPOVETSKY considera que en el período denominado posfordismo ha nacido "un 'Homo consumericus' de tercer tipo, una especie de turboconsumidor desatado, móvil y flexible, liberado en buena medida de las antiguas culturas de clase, con gustos $y$ adquisiciones imprevisibles. Del consumidor sometido a las coerciones sociales del 'standing'se ha pasado al hiperconsumidor al acecho de experiencias emocionales y de mayor bienestar, de calidad de vida y de salud, de marcas y autenticidad, de inmediatez y comunicación”" (LIPOVETSKY, 2007: 10-11).

La conformación de periferias urbanas de alta renta y dedicadas a los sectores sociales más solventes constituye una de las formas en que el hiperconsumo ha cristalizado territorialmente. La dispersión espacial y el consumo exacerbado de recursos (energéticos y naturales), por un lado, y los discursos que las construyen (y justifican), por otro lado, estarían dando cuenta de ello. Sin embargo, la constitución de las periferias urbanas tiene sus especificidades históricas y geográficas, y tanto es así que en ocasiones dicho modelo del hiperconsumo se da en contextos espaciales cuya criticidad termina por producir el efecto contrario al buscado.

Lo que se presenta a continuación es una aproximación histórica al proceso de conformación de la periferia urbana en la ciudad de Santa Fe (Argentina). Actualmente esta consiste en una comuna autónoma (San José del Rincón), un área perteneciente al municipio de Santa Fe (Colastiné Norte y Sur) y dos áreas de asentamientos informales, también del municipio (La Guardia y Alto Verde). El proceso de urbanización de este espacio fue discontinuo y se extendió un siglo: desde la primera traza ferroviaria en 1886 hasta la habilitación de las urbanizaciones a partir de la segunda mitad del siglo XX. Aquí se hará foco en este último período, caracterizado por la subdivisión y la urbanización del área

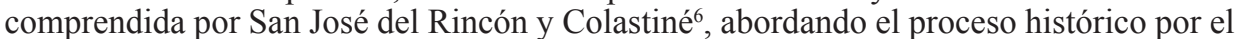
cual una zona rural, dedicada principalmente al cultivo de pequeña escala, situada en un medio hídricamente crítico (por ser el valle de inundación del río Paraná), se transformó en dos décadas en una promisoria área de renta urbana, destinada a la residencia de los sectores sociales medios. Por un lado, se identificará el proceso histórico desde lo físicoespacial y, por otro lado (aunque en estrecha relación), se abordará el caso desde el plano simbólico, es decir, el proceso de construcción de las relaciones entre las características de la urbanización y los valores sociales asociados a ella y estrechamente en consonancia 
El paradigma del hiperconsumo en contextos espaciales ambientalmente críticos. Santa Fe (Argentina) y la urbanización del valle aluvial del río Paraná a finales del siglo xx

con el modelo social del hiperconsumo. Lo que se presenta son algunas conclusiones obtenidas de una investigación más amplia que constituyó una tesis doctoral centrada en dicha problemática.

\section{LA URBANIZACIÓN DEL VALLE DE INUNDACIÓN: EXCEPCIÓN LEGAL Y NUE- VO MODELO TERRITORIAL}

La ciudad de Santa Fe se encuentra ubicada en la zona del centro-este argentino, y funciona desde la constitución del Estado moderno como capital provincial. Desde la perspectiva hídrico-geográfica, se ubica en el interfluvio de los ríos Salado (al oeste) y Paraná (al este). Posee tres bordes fluviales, y solo el norte le concede extenderse por tierra firme. Su suelo llano, sumado a la particularidad de poseer casi todos sus frentes fluviales, ha determinado una condición hídrica altamente crítica que fue delineando gran parte de su historia. Y así como la complejidad del medio hídrico ha ido moldeando a la acción humana, también los artificios antrópicos han intentado avanzar sobre el medio natural inestable con el objetivo de dominarlo. Ya fuera como justificativo o como condición ineludible, lo cierto es que el agua ha trazado la historia de la ciudad, y tanto la figura del inundado como la del isleño perviven en la sombra y eventualmente emergen en cada creciente de los ríos.

En la última década del siglo XX, la periferia Este de la ciudad de Santa Fe (que hasta ese momento era eminentemente rural) sufrió un intenso proceso de ocupación urbana sobre el valle de inundación. Por tratarse de una ocupación mayoritariamente residencial en un área hídricamente crítica, comenzaron a debatirse, tanto en el ámbito académico como en algunos organismos públicos, su viabilidad y sostenibilidad a medio plazo. La problemática ha sido tratada por la prensa local (tanto desde una visión que la promueve como desde su crítica), y ha sido tema de numerosas publicaciones y proyectos de investigación en la Universidad Nacional del Litoral en diversas áreas disciplinares, como la Geografía, la Arquitectura, las Ciencias Hídricas, y en los estudios urbanos en general. También ha sido tema de conferencias y debates organizados tanto en el ámbito académico local como desde la administración municipal. Sin embargo, los estudios realizados se han mantenido principalmente dentro de los márgenes disciplinares, y por lo tanto, no se han realizado investigaciones integrales sobre el proceso histórico de urbanización. 


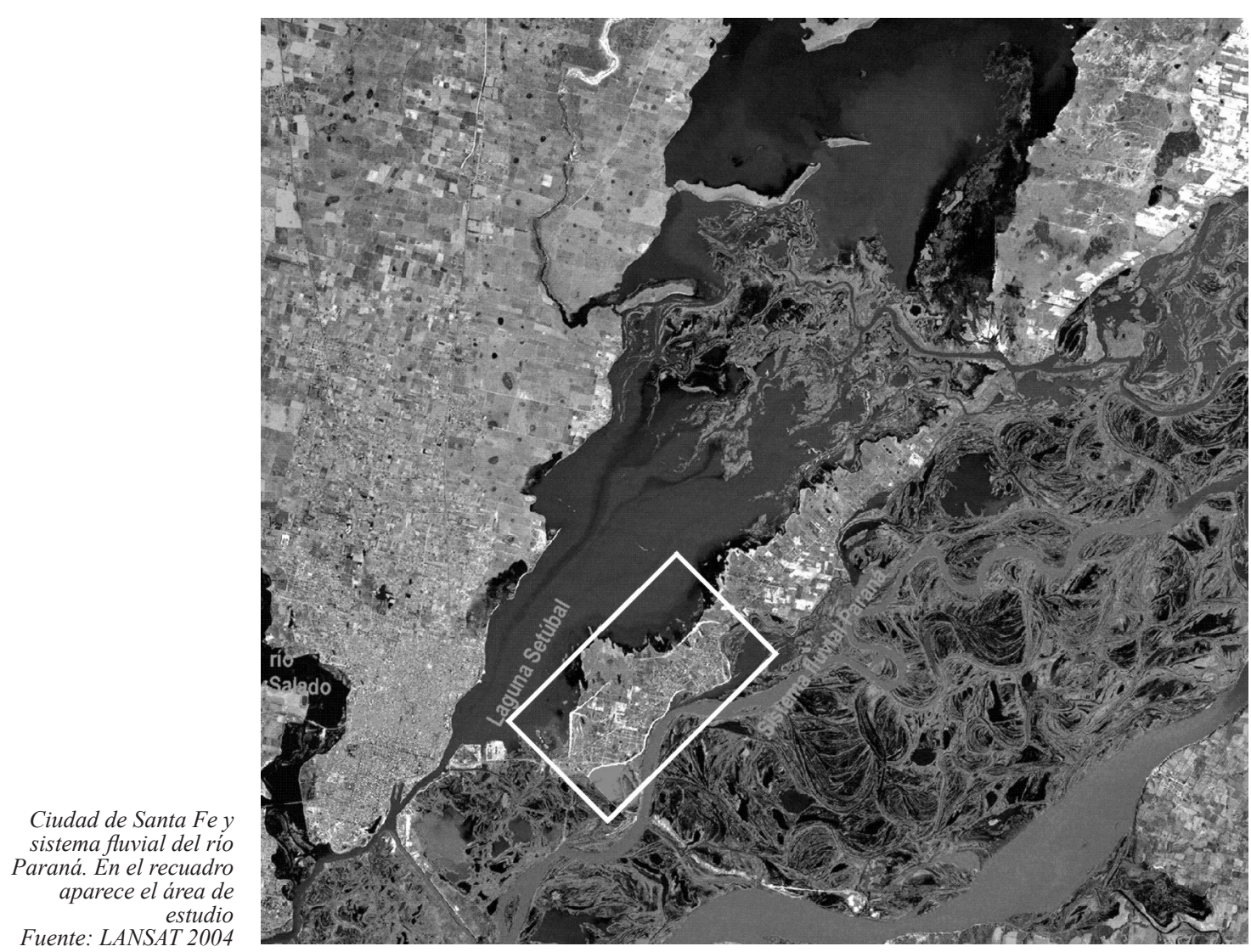

Los inicios de dicho proceso pueden remitirse a las décadas de 1960 y 1970. En la primera década del siglo XXI, el extrarradio urbano este de Santa Fe ya se había constituido en un área principalmente residencial y de alto valor simbólico. El desarrollo de tal proceso fue habilitado en 1959 por la derogación de la Ordenanza Municipal N. ${ }^{\circ} 3864$ del año 1939. Esta última establecía una serie de restricciones y exigencias a la urbanización del área. La Ordenanza Municipal N. ${ }^{\circ}$ 4772/59 suspendió la vigencia de la sancionada en 1939, y 
El paradigma del hiperconsumo en contextos espaciales ambientalmente críticos. Santa Fe (Argentina) y la urbanización del valle aluvial del río Paraná a finales del siglo xx

expresó como objetivo perfeccionar el régimen de ocupación. Sin embargo, las nuevas normas que debían dictarse (para reemplazar la ordenanza derogada) nunca se concretaron, y la aprobación de las subdivisiones quedó a cargo de la Dirección de Catastro Municipal, bajo un régimen que no presentaba restricciones ni regulación alguna. Se inició así un proceso de urbanización por la vía de la excepción legal (ya que la ordenanza de 1959 no daba lugar a la subdivisión hasta el dictado de las nuevas normas), y en ausencia de un cuerpo normativo que fijase pautas mínimas de ocupación territorial, la única lógica que orientó los loteos y la ocupación fue la del mercado inmobiliario.

El destino hacia la urbanización de las antiguas áreas rurales ya no tenía retroceso. Tanto fue así que en el año 1964 el presidente del bloque de concejales del MIR presentó un proyecto para construir un museo en San José del Rincón con el fin de conservar "los elementos tradicionales de la antigua vida en los establecimientos rurales" (DIARIO EL Litoral, 23 de septiembre de 1964). Sin duda se trató de un intento por preservar lo que creía que se estaba perdiendo.

La anulación de la ordenanza de 1939 y el posterior olvido respecto de formular un nuevo marco regulatorio - si bien no pueden considerarse acciones intencionales del municipio (cuya finalidad sería la urbanización desregulada) - no estaban exentos de una voluntad tendenciosa. La ordenanza de 1959 fue muy conveniente para un sector de la sociedad que había adquirido parcelas rurales a muy bajo precio y una década después las incorporaba al mercado inmobiliario como tierra suburbana, con un importante valor diferencial sobre las rurales. Además, es importante remarcar que la ocupación del valle no fue una transgresión legal; no se dio en un marco de ilegalidad, sino que fue habilitada por una norma que anulaba la regulación. En este sentido, puede decirse que el vacío jurídico habilitado por la ordenanza de 1959 implicó el establecimiento de una coincidencia entre lo jurídico y lo no jurídico que abrió paso a la desactivación de las distancias (en cuanto a capacidad de acción) entre lo público y lo privado. En tales condiciones, el rol del agente público de regular la urbanización quedó anulado, y el proceso de urbanización (con la posterior ocupación del valle) quedó en manos del sector privado, bajo la única lógica (o ley) del mercado. Sintetizando, puede decirse que las acciones de subdivisión de la tierra fueron habilitadas por una decisión estatal que dio lugar a la instauración del sector privado y su lógica, como autoridad y motor principal en la gestión de ese territorio.

En los relevamientos catastrales puede verse que en 1960 el área sobre el albardón en torno de San José del Rincón se estaba subdividiendo intensamente, si se la compara con el relevamiento del año 1935. ${ }^{7}$ Entre los años 1947 y 1960 la población pasó de 3490 habitantes a $7119^{8}$, es decir que creció al doble, mientras la ciudad en su área consolidada tuvo un crecimiento que rondó un $20 \%$.
7- Entre 1935 y 1960 no se han encontrado más registros planimétricos oficiales en los que aparezca la periferia Este de Santa Fe. El plano de 1935 es el último plano municipal que representa a este sector, $y$ los siguientes corresponden a relevamientos del IGM. 
8- Se tomó la cantidad de habitantes para San José del Rincón, Alto Verde, La Guardia y Colastiné Fuente: IPEC Censo Nacional de Población y Vivienda, 1947 y 1960.

9- Ordenanza N. ${ }^{\circ} 7871$ del 14 de agosto de 1980. Municipalidad de Santa Fe.
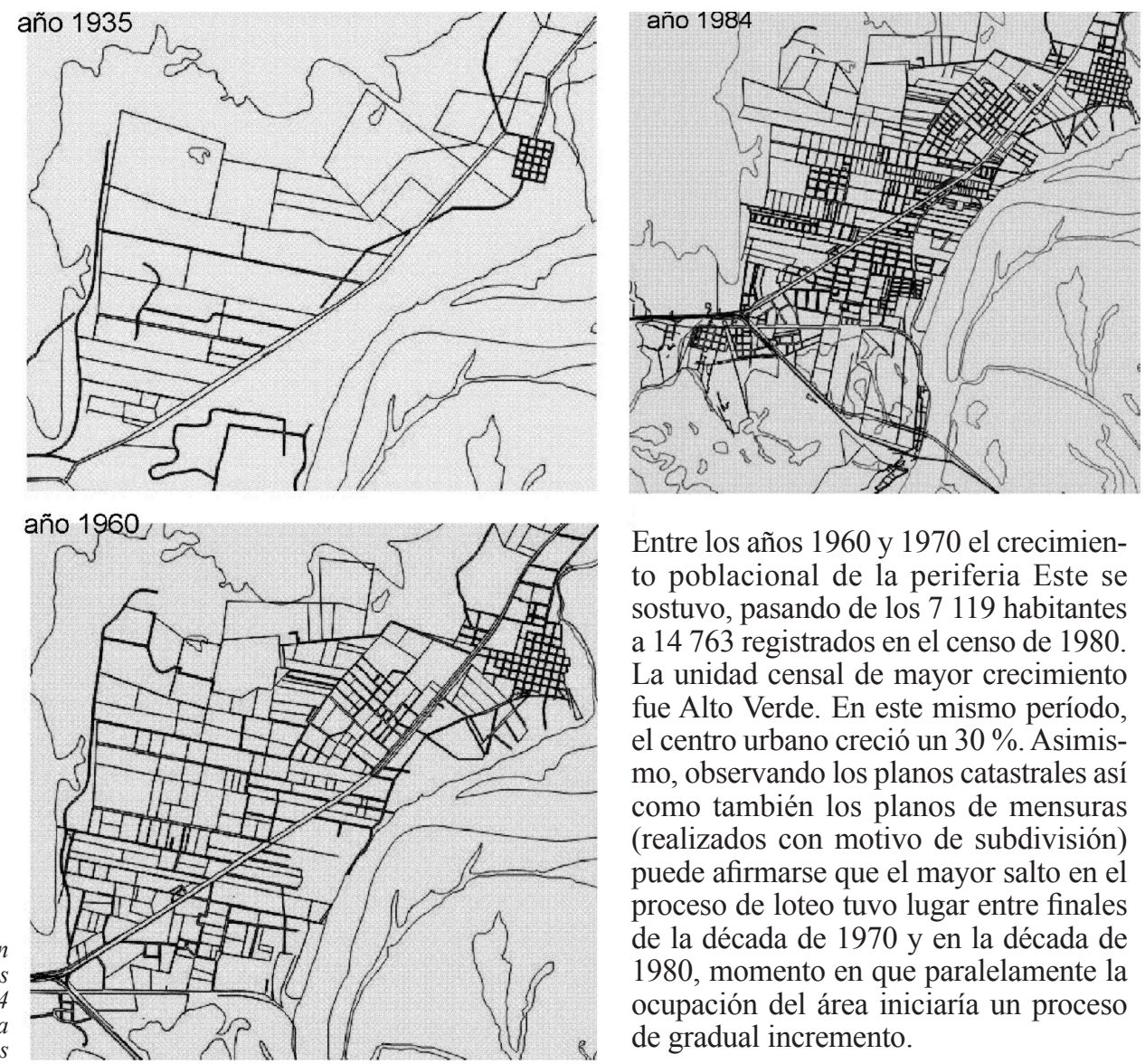

Entre los años 1960 y 1970 el crecimiento poblacional de la periferia Este se sostuvo, pasando de los 7119 habitantes a 14763 registrados en el censo de 1980 . La unidad censal de mayor crecimiento fue Alto Verde. En este mismo período, el centro urbano creció un $30 \%$. Asimismo, observando los planos catastrales así como también los planos de mensuras (realizados con motivo de subdivisión) puede afirmarse que el mayor salto en el proceso de loteo tuvo lugar entre finales de la década de 1970 y en la década de 1980, momento en que paralelamente la ocupación del área iniciaría un proceso de gradual incremento.

En el año 1980 se aprobó el Plan Director de la ciudad de Santa Fe. ${ }^{9}$ El principal interés del plan era orientar el crecimiento de la ciudad hacia la margen este, ocupando el albardón perteneciente al valle de inundación del río Paraná. Tal orientación se justificó a partir de la "necesidad" de recomponer la relación entre la ciudad y el río a través de una serie 
El paradigma del hiperconsumo en contextos espaciales ambientalmente críticos. Santa Fe (Argentina) y la urbanización del valle aluvial del río Paraná a finales del siglo xx

de obras de ingeniería que se complementaban con el contemporáneo proyecto hidroeléctrico Paraná Medio. Pero también estaba en los objetivos del plan establecer cierto orden en el proceso de urbanización ya iniciado, a partir de su regulación. Para ello, esbozaba una zonificación sobre la base de grados de urbanización, que intentaba, como se dijo, regularizar la ocupación "de hecho" en las áreas perimetrales de la ciudad..$^{10}$ La zonificación del plan establecía un área urbana correspondiente al centro urbano, y para la periferia Este determinaba la condición de suburbana en las zonas que superan la cota 15 , y la condición de área anegadiza por debajo de ese nivel. ${ }^{11}$ Con tal determinación, toda el área definida como anegadiza ya no era pasible de urbanizarse. El plan definió a las áreas suburbanas como "aquellas de baja densidad edilicia y poblacional, pero potencialmente aptas para usos residenciales". A pesar de que en ese momento aún no se habían construido las defensas hidráulicas ${ }^{12}$ y que en cada crecida del río Paraná las aguas ocupaban buena parte de la zona, el plan estaba sugiriendo la posibilidad de constituir un espacio para el establecimiento de residencias.

En consonancia con el proceso de urbanización, durante las décadas posteriores a 1960, el Estado (nacional y provincial) dio impulso a una serie de obras de infraestructura con el objetivo de establecer comunicaciones más eficientes en el territorio nacional. Se construyeron así los últimos tramos de la ruta provincial N. ${ }^{\circ} 1$, que
10- No solo la periferia Este estaba en proceso de urbanización informal, sino también el borde oeste de la ciudad, en la margen del río Salado, que había sido habilitada por la construcción de la defensa hidráulica denominada Terraplén Irigoyen.

11- Este nivel de cota como limite fue establecido por el Instituto Geográfico Militar.

12- Existian terraplenes precarios puntualmente ubicados, pero no habia iniciativa política para construir infraestructura especifica.

Plano de mensura y subdivisión en Villa California año 1977. Superficie loteada: $137275 \mathrm{~m}^{2}$

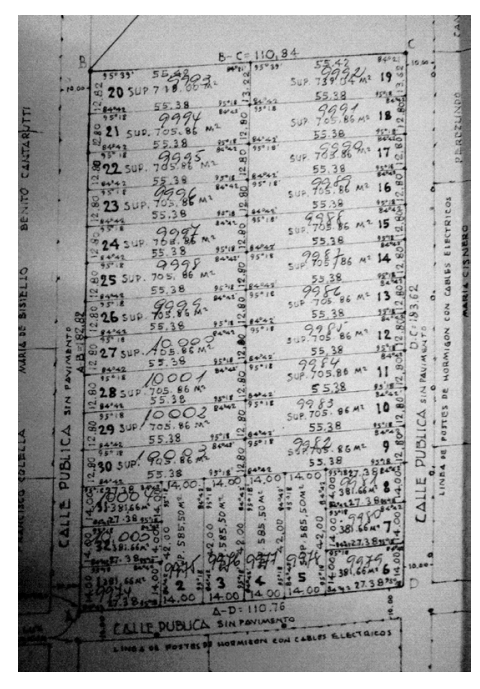

Plano de mensura y subdivisión en Villa California, año 1978. Superficie loteada: 20 $206 \mathrm{~m}^{2}$

Fuente: Archivo de Catastro de la Municipalidad de Santa Fe 
comunicaba con las localidades del norte provincial, y la ruta nacional N. ${ }^{\circ} 168$, que comunicó Santa Fe con la provincia de Entre Ríos.

A mediados de los 90 se construyó un anillo defensivo contra inundaciones, obra que estuvo a cargo del Ministerio de Obras Públicas provincial. Este sería el hecho definitivo que por un lado confirmaría lo habilitado por la ordenanza de 1959 y, por otro lado, estimularía la intensa ocupación del albardón durante los últimos dos años del siglo XX y los primeros del siguiente. Con la defensa sin duda se le daba el mayor impulso a un proceso que ya se había anticipado algunos años. Pero asimismo, tal acontecimiento debe observarse a la luz de lo que estaba ocurriendo en el contexto nacional. Las dos últimas décadas del siglo XX estuvieron signadas por un proceso que Maristella Svampa (2001: 14-16) definió como pasaje de un modelo de ciudad abierta a otro de ciudad cerrada. Este pasaje no solo implicó cambios en los modos de sociabilidad, sino que también llevó consigo una reorganización espacial urbana. Esta consistió mayormente en un pasaje de un modelo basado en la noción de espacio público, valor ciudadano e integración social ligado a la tradición europea (cuya forma espacial es la ciudad tradicional), con su mixtura social y cultural, a otro modelo relacionado con las formas de sociabilidad norteamericanas, intensamente individualistas y patrimonialistas, donde sería central la figura del contribuyente y consumidor. La morfología urbana derivada de este modelo se expresó en los enclaves urbanos, social y funcionalmente homogéneos.

Como han analizado Diego Ríos y Pedro Pírez (2008: 100), en Buenos Aires, este fenómeno de urbanizaciones cerradas o de organización en enclaves se intensificó a mediados de la década del 90. Para el autor, "esta última expansión de $U C^{13}$ se enmarca en la modificación de la articulación público-privado ocurrida en los años noventa en Argentina, vinculada a la disminución de las inversiones públicas, al apoyo estatal a la actividad privada y al papel protagónico de las inversiones privadas en la producción del espacio urbano" (Ríos, 2008: 101).

Se conformó así un enclave urbano sin planificación alguna, el cual, al mismo tiempo que se promocionaba como un espacio idílico y privilegiado para la residencia, carecía en realidad de los servicios urbanos más básicos (cloacas, desagües pluviales, gas natural, por ejemplo), y se encontraba situado en el valle de inundación del río Paraná. 
El paradigma del hiperconsumo en contextos espaciales ambientalmente críticos. Santa Fe

(Argentina) y la urbanización del valle aluvial del río Paraná a finales del siglo xx

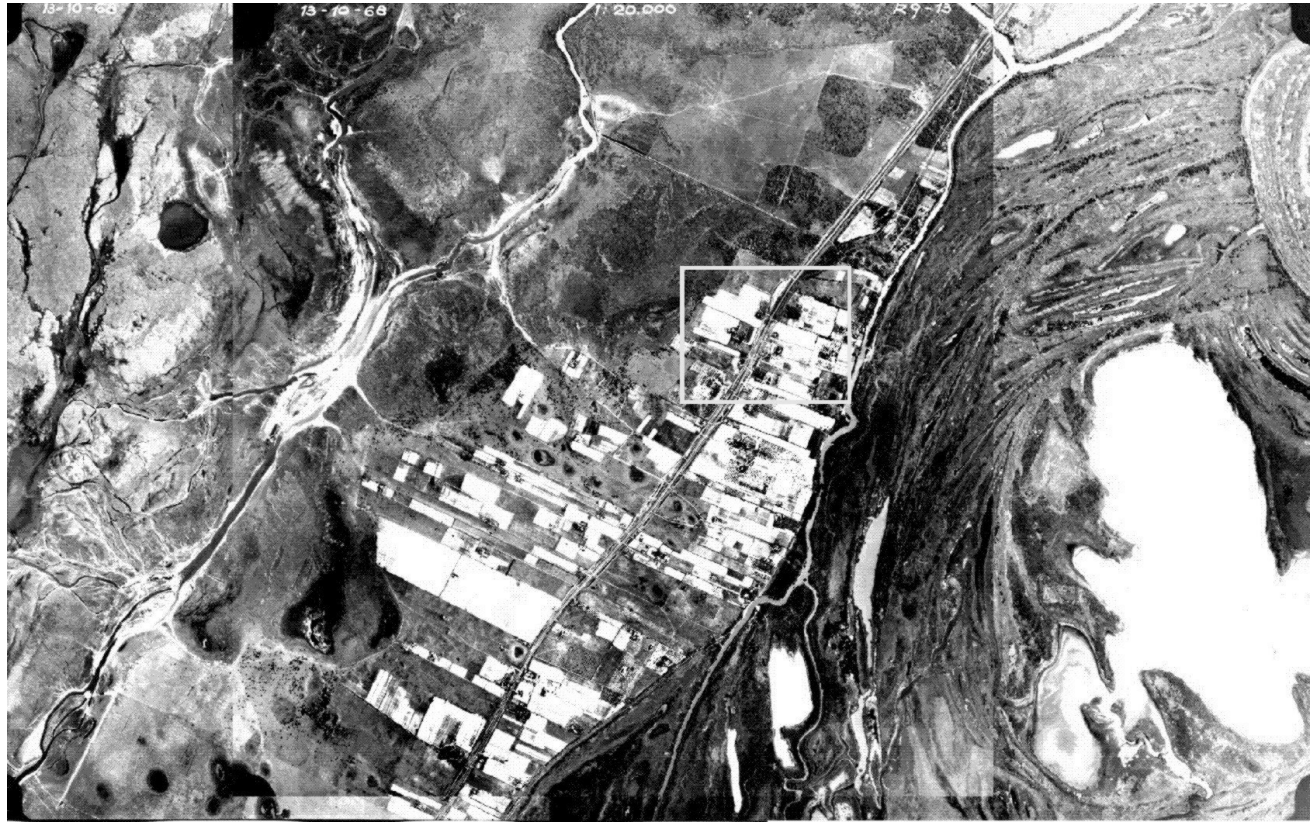

DEL VERDE COMO REDENCIÓN AL VERDE COMO VALOR: EL PROCESO DE CONSTRUCCIÓN DISCURSIVA DE LA PERIFERIA URBANA SANTAFESINA

El proceso de urbanización antes expuesto se fue configurando (pero también sosteniendo y justificando) a partir de lo que denominamos la construcción discursiva de la periferia Este santafesina. Es decir, un conjunto de enunciados que fueron aportando, en sus variaciones y a través del tiempo, a la construcción del mismo objeto. Los tres "focos" de enunciación que se analizaron fueron los siguientes: la prensa escrita, los documentos de los planes urbanos y la publicidad inmobiliaria. Esta última apareció en los primeros años del siglo XXI, cuando el área comenzó a promocionarse discursivamente como semejante a los barrios privados.
Fotografia de Villa California y Rincón en 1968. Se observa la predominancia de las parcelas rurales. Fuente: Archivo de Catastro de la municipalidad de Santa Fe (el recuadro pertenece al sector mostrado en Fig. 6); y Fig. 6: Fotografía de Villa California y Rincón en 2006. Se observa la trama urbana en torno a la ruta $N .^{\circ} 1$

Fuente: imagen de satélite obtenida con Google Earth 
14- Se han relevado los diarios Santa Fe, El Orden y El Litoral.

15- Se distingue debido a que se trata de la idea de naturaleza construida culturalmente.

16- El área que hasta ese momento no era considerada por el habitante urbano comienza a pensarse (discursivamente y en una incipiente práctica) como lugar para el descanso en los días no laborables.

17- A través de la construcción de infraestructura vial, entre otras obras. Aqui no se desarrolla el proceso debido a que excede el recorte temporal del artículo.

18- Refiriéndose a los enclaves residenciales de finales del siglo XX, MARISTELA SVAMPA dice: "el paraíso tiene un solo color" (SVAMPA, 2004: 87).

19- Que por supuesto contenía reminiscencias del Higienis mo de los siglos XVIII y XIX.
En la prensa escrita local ${ }^{14}$, desde la década del 30, comenzó a hacer aparición la idea de paisaje. Esta noción funcionaría como campo de justificación para la progresiva incorporación de la naturaleza ${ }^{15}$ al mercado inmobiliario, a través de la idea de uso urbano de un ámbito que antes era mayormente rural o sin uso definido. ${ }^{16} \mathrm{Si}$ la apropiación física de un espacio determinado implica el acceso a él, entonces la noción de paisaje (que lleva consigo la idea de apropiación a través de la mirada) constituyó un elemento discursivo eficaz en el proceso de apropiación simbólica, y al mismo tiempo la justificación para su apropiación física. ${ }^{17} \mathrm{Y}$ asimismo, dicha idea de paisaje, asociada a la contemplación y al usufructo de la naturaleza, decimos que contribuyó a la posterior construcción de un ideario sobre el área que asociaba privilegios sociales con lo verde. A finales del siglo, la valoración del paisaje en las periferias residenciales exigía que contuviera la idea de lo verde. ${ }^{18}$

Debe reconocerse, sin embargo, que esta idea de lo verde ya estaba presente entre los valores sociales. La modernidad y el Urbanismo moderno, en particular, hicieron del verde el elemento que supuestamente brindaría al ciudadano un confort digno, pero también el desahogo necesario frente a la vida en la ciudad industrial. Luz, aire y verde se convertirían (según este imaginario ${ }^{19}$ ) en las partes integrantes del pulmón para contrarrestar las epidemias, devolviendo al espíritu aquella pureza supuestamente perdida en la ciudad moderna. En el Plan Regulador para Santa Fe de 1947, los espacios verdes se concebían como los lugares donde encontrar aire puro, y por lo tanto, la ciudad se posicionaba como el lugar de la contaminación. Desde esa perspectiva, el restablecimiento del equilibrio del habitante urbano solo tenía lugar en un ambiente no urbano, y tal equilibrio no solo sería fisiológico, sino también espiritual: "constituye obra de buen gobierno, proporcionar abundancia de espacios libres en los cuales los seres humanos se concilian con la naturaleza, purifican sus organismos, recrean sus pupilas, y se entregan a la placidez y a la recreación, diluyendo el amargor de las preocupaciones agobiadoras y acrecentando el apego a la existencia por el prodigio de la felicidad" (Plan Regulador de Santa Fe, 1947: 111).

A finales del siglo XX, ese discurso del plan regulador en el cual lo verde se consideraba un bien público (que estaba en el deber del municipio brindar a sus ciudadanos) fue adquiriendo otras características. El Plan Director de 1980 ya no promovía la abundancia de espacios verdes, sino que se interesaba por el resguardo de los existentes, frente a posibles modificaciones u ocupación (Plan Director, 1980: 97). Pero a pesar de la insuficiencia de espacios verdes expresada por el plan, su consideración como un bien público que el Estado debía contemplar y administrar permaneció sin modificación. No obstante, la debilidad del plan para instaurarse como instrumento de transformación efectiva dejó en el plano de las intenciones dichas consideraciones, y lo verde en la periferia Este santafesina 
El paradigma del hiperconsumo en contextos espaciales ambientalmente críticos. Santa Fe

(Argentina) y la urbanización del valle aluvial del río Paraná a finales del siglo xx

se iría convirtiendo, a medida que ingresaba la década del 90, en un valor asociado a los privilegios de un sector muy específico de la sociedad.

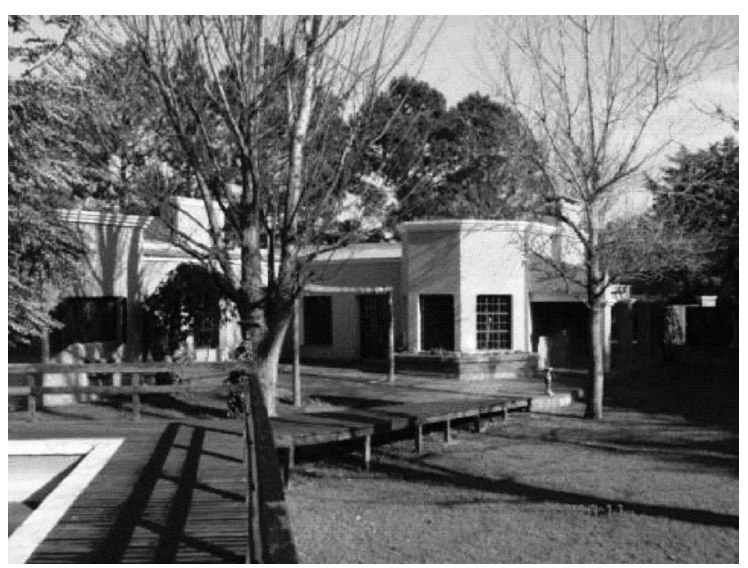

A principios del siglo XXI, esta idea del verde, que fue asociado a la exclusividad por un lado, y a la seguridad por otro, ya se encontraba instalada. Así, pueden verse en la publicidad de los loteos en la costa un único color de fondo (el verde) y un discurso recurrente en el cual términos como sueños, tranquilidad, placer, naturaleza, seguridad se intercambian indistintamente, ya que todos estaban diciendo lo mismo: "la vida fuera de la ciudad es mejor". De este modo, la naturaleza, expresada en el concepto de lo verde fue directamente asociada a nociones como tranquilidad y sociabilidad, oponiéndose, en tal asociación, a la ciudad que se define como caótica, gris, agresiva. Dentro de este esquema discursivo, la homogeneidad se torna el lugar de la posible sociabilidad, aunque tal eventualidad solo pueda darse dentro de los límites del enclave.

Asimismo, mientras algunos discursos promocionaban la idea de vida en equilibrio con la naturaleza, en un entorno amigable, quedaba al descubierto una realidad muy distinta: en el valle de inundación las capas freáticas se encuentran a muy escasa distancia de la superficie, y la inexistencia de una red de cloacas implicaba (y aún actualmente lo hace) la contaminación del agua y del suelo próximos. Asimismo, al no existir red de agua potable, el agua de consumo es extraída de algunas de esas mismas capas, algo más profundas.
Residencias en Colastiné, año 2010

Fuente: imágenes propias 
20- La amplia oferta de terrenos y el bajo costo en relación con el centro urbano incentivaron en un momento crítico de la economía argentina - años 2000 y 2001-el desplazamiento hacia esta área periférica.

21- Entre los años 2000 y 2001 se dio el pico más alto en negocios inmobiliarios de la zona. Fuente: entrevista realizada en la principal inmobiliaria de la costa.

22- Ya que los humedales son definidos como ecosistemas débiles.
La fuerza que han tenido una serie de circunstancias ${ }^{20}$ y discursos (no solo el de lo verde) ha posibilitado que una buena parte de la sociedad santafesina desde el año $2000^{21}$ eligiera ubicar su residencia en el valle de inundación del río Paraná. En el lapso de más de medio siglo, la noción de lo verde asociada a la idea de paisaje ha variado en estrecha relación con los usos del área, siendo en un primer momento objeto de contemplación y disfrute para la purificación del habitante urbano que podía acceder a él, luego pasando a ser un derecho administrado por el Estado y sobre el final del siglo XX convertido en un privilegio y objeto de prestigio de los sectores sociales solventes, al servicio principalmente de los intereses privados. Y este último complejo discursivo constituyó, sin duda, uno de los factores decisivos para que una parte de la sociedad santafesina eligiera como lugar de residencia un área caracterizada por la inestabilidad ambiental ${ }^{22}$, con condiciones hídricas críticas y notable precariedad respecto de los servicios urbanos básicos.

\section{CUESTIONES FINALES SOBRE LA ESPECIFICIDAD DEL CASO SANTAFESINO}

Se ha expuesto una serie de características que el desarrollo residencial en la costa santafesina comparte con el modelo más generalmente difundido de barrios cerrados. Pero existen también algunas particularidades del caso, que destacamos a continuación.

La primera cuestión hace referencia al modo diferencial en la gestión de la tierra de la periferia santafesina en relación con el modelo más difundido. El modelo residencial denominado en Argentina tipo country generalmente surge por las acciones de un desarrollador urbano, es decir, existe un propietario (o empresa propietaria) que decide subdividir la tierra y urbanizar un predio. Este emprendimiento lleva consigo altos costos económicos, que se trasladan a los futuros residentes en términos de precio del lote, de las expensas que se pagan mensualmente y de las matrículas de ingreso (que no existen en todos los barrios). Puede decirse entonces que la residencia en estos barrios es una elección por la cual se acepta pagar más por vivir en un ambiente que se considera mejor que la ciudad. Esto sucede en general en Argentina, donde este tipo de urbanizaciones se desarrollan dentro de un régimen privado.

Por el contrario, en el área estudiada de la ciudad de Santa Fe, tanto los barrios Villa California como Colastiné Norte y Rincón se han ido formando con una voluntad de vida country, observable en el patrón disperso de ocupación del suelo, en la estética edilicia (altamente influida por los modelos globales) y en una explícita búsqueda de homogeneidad socioeconómica (generalmente los residentes son familias jóvenes del sector social 
El paradigma del hiperconsumo en contextos espaciales ambientalmente críticos. Santa Fe (Argentina) y la urbanización del valle aluvial del río Paraná a finales del siglo xx

medio). Este tipo de ocupación, por su dispersión territorial y por el tipo de residencia que es la vivienda unifamiliar en lotes de dimensiones importantes, requiere en consecuencia mayor consumo de energía, y la producción de desechos se exacerba en relación con la ocupación de tipo compacto característica de los centros urbanos. Frente a esto, al no existir un desarrollador urbano que se encargue de implementar los servicios básicos, la gestión de la tierra se realiza a partir de su subdivisión y venta, como ocurre normalmente en las ciudades, pero en una situación de excepción legal (recordemos la derogación de la ordenanza de 1938). Tales acciones condujeron a la apertura de calles e instalación de residencias bajo un modo de ocupación cuya sostenibilidad es escasa debido a los altos costos económicos que implicaría dotar a la zona de los servicios necesarios. En tales circunstancias, puede decirse que tiene lugar un traspaso de los costos de urbanización desde el sector privado al ente Estado. Los agentes privados obtuvieron la renta en el proceso de conversión de tierra rural a urbana, mientras que los costos más altos de urbanización y equipamiento fueron transferidos al municipio. ${ }^{23}$ Tanto el anillo defensivo contra inundaciones del año 1994 como el proyecto de remodelación de la ruta provincial N ${ }^{\circ} 1$ muestran esta situación, en la cual el Estado debe hacer frente a los costos para seguir manteniendo esta urbanización. Para tener una idea, podemos mencionar el caso de la ruta N. ${ }^{\circ} 1$, cuyo proyecto del año 2006 (aún no concretado) rondaba los 35.000.000 de pesos, y en 2011 (con algunas modificaciones que se consideraron necesarias) ascendió a poco menos de 169.000.000 de pesos (diario El Litoral, 6 de agosto de 2011). El proyecto de la ruta se difunde desde la prensa como una obra necesaria frente a las insuficiencias de la actual ruta, que debe hacer circular más de 15.000 vehículos diarios, de los cuales se estima que un $60 \%$ no llega más allá de Rincón. Asimismo, el proyecto incluye obras de desagüe, ya que la existente defensa hídrica actúa de barrera cuando las precipitaciones poseen grandes magnitudes, provocando la inundación de las áreas residenciales. Es decir, al gasto por la construcción de la defensa (en 1994) ahora se le suma el gasto para mitigar los efectos no previstos, intensificados por la ocupación residencial que ha ido obstruyendo las vías de escurrimiento. Y el área continúa urbanizándose.

Otra cuestión se refiere a las motivaciones para elegir como lugar de residencia la costa. En Santa Fe existen barrios cerrados más tradicionales cuya elección sin duda está sustentada en un estilo de vida con determinada calidad y disponibilidad de servicios por los cuales el residente paga. En la costa, en cambio, los valores de los terrenos, así como el de las viviendas construidas, son sensiblemente menores que los del centro urbano. A modo de ejemplo, un lote de $500 \mathrm{~m}^{2}$ en Altos del Rincón, emprendimiento inmobiliario de una empresa local ubicado próximo a la ruta 1, valía en el año $200835000^{24}$ pesos, es decir,
23- Si bien existen impuestos por el loteo, su valor es considerablemente menor que en el centro urbano.

24-Fuente: http://www.inmobiliariabernardi.com. 
${ }^{25}$ Fuente: Ibídem.

${ }^{26}$ Fuente: Ibidem.

Fotografia publicada en el diario El Litoral, 6 de Agosto de 2011, en reclamo por la remodelación de la ruta $N^{\circ} 1$.

Fuente: Diario El Litoral

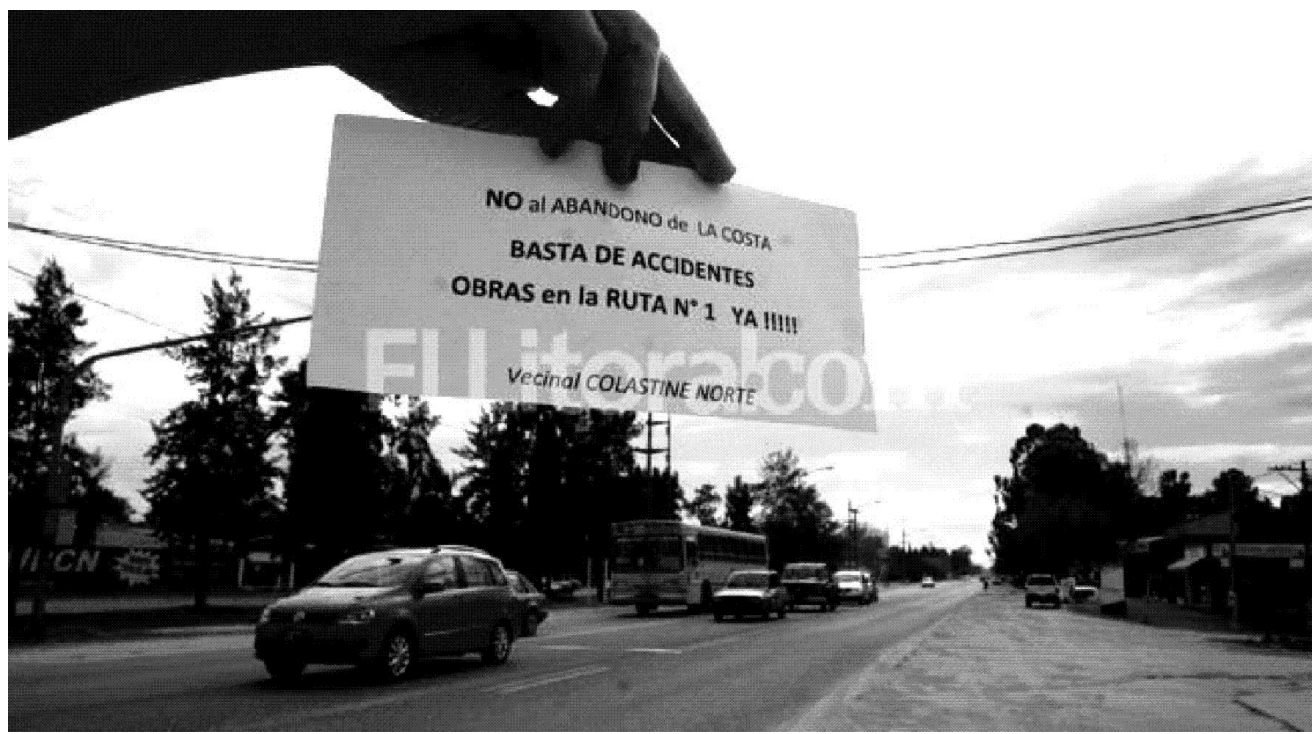

69 pesos el $\mathrm{m}^{2}$. Estas cifras contrastan con los 310 pesos que valía, en el mismo año, el $\mathrm{m}^{2}$ de un terreno ubicado en un barrio de jerarquía media del centro urbano santafesino ${ }^{25}$. De la misma manera, en Villa California, uno de los barrios más emblemáticos y de mayor valor de la costa, se ofrecían en 2008 terrenos de $1000 \mathrm{~m}^{2}$ valuados en 74000 pesos $^{26}$, es decir, con un costo de 74 pesos el $\mathrm{m}^{2}$. En la ciudad, por el contrario, el metro cuadrado en una zona de escaso aprecio por parte de las clases medias ya valía 89 pesos.

De esto se desprende que el éxodo de un sector de la población hacia la periferia Este se relaciona con un aumento en las áreas centrales (preferidas por las clases medias) de los valores del suelo, como así también el rechazo por la vida en un entorno densificado. Ya se dijo que el período más próspero en negocios inmobiliarios en el área fue entre los años 2000 y 2001, momento en que los sectores medios de Argentina fueron seriamente afectados por la crisis económica que atravesaba el país. En circunstancias económicamente adversas, estos sectores optaron principalmente por la continuidad del estilo de vida en áreas de menor valor, como es el caso de "la costa". 
El paradigma del hiperconsumo en contextos espaciales ambientalmente críticos. Santa Fe (Argentina) y la urbanización del valle aluvial del río Paraná a finales del siglo xx

Otra cuestión que diferencia a la costa del modelo más difundido de enclaves suburbanos es la "calidad" del espacio público. Podría decirse que este resulta de la inexistencia de muralla perimetral y de sistemas de seguridad comunitarios. Tanto San José del Rincón como Colastiné no funcionan como barrios cerrados. Como se explicó antes, el espacio por fuera de los terrenos privados pertenece al municipio y, por lo tanto, quienes residen allí han optado por medidas de seguridad individuales en la propia vivienda. En estas condiciones, y en aras de maximizar la seguridad (que se entiende como exclusión del otro $^{27}$ ), las residencias aparecen amuralladas y se desarrollan de manera introvertida. El espacio de la calle se convierte, por tanto, en un simple corredor con sucesivas murallas que solo se utiliza para circular en vehículos motorizados, y que gradualmente se va deteriorando en su calidad. ${ }^{28}$ Queda en entredicho, entonces, esa sociabilidad ampliamente difundida que aparecería como propia de estos barrios, y que, sin embargo, en la costa difícilmente puede verificarse. La sociabilidad solo se encuentra en las residencias familiares, es decir, entre muros.

Una última cuestión que se considera relevante para destacar se relaciona con la sostenibilidad en términos económicos y ambientales de esta urbanización periférica. Históricamente las periferias urbanas han funcionado como el espacio para el abastecimiento de los centros urbanos, siendo reservas de alimentos y de agua, o bien simplemente haciendo de barrera natural en situaciones específicas como las inundaciones (en las que el suelo funciona como medio de absorción). En el caso de la costa, por tratarse del valle de inundación del río Paraná, la función específica del área es la de constituir el reservorio del cauce fluvial durante las crecidas periódicas y las extraordinarias. Por lo tanto, la ocupación de esta área implica, en primera instancia, que el cauce del río Paraná tomará otro curso (no previsto) en futuras inundaciones, posiblemente socavando zonas de la ciudad (con el consecuente incremento en la demanda de gasto público que esto significa) o directamente inundando las áreas que han quedado por fuera del anillo defensivo (la comuna de Arroyo Leyes, por ejemplo). Pero asimismo, la ocupación de ese suelo, que hasta mediados del siglo XX era un espacio destinado al cultivo de pequeña escala (para la comercialización local), ha provocado, en primer lugar, que los alimentos allí producidos ahora deban adquirirse a mayor distancia, aumentando tanto su costo como el uso de vehículos de transporte:29 y en segundo lugar, ha tenido lugar la antropización irreversible de un espacio que a partir de la urbanización no podrá volver a cumplir con sus funciones específicas (de humedal) en el sistema fluvial.

Santa Fe no es una ciudad densa si se la compara con otras ciudades argentinas como Buenos Aires, Rosario o Córdoba. Mientras en el Departamento Rosario se han calcula-
27- El otro como el diferente el que no pertenece al barrio.

28- Se tira basura, no se reparan veredas rotas ni cunetas degradadas, por ejemplo.

29- Cuanto mayores distancias tengan que recorrerse para obtener los productos, más aumentará la cantidad de vehículos en las rutas, con lo cual además del mayor gasto energético y producción de contaminación del aire, el gasto público irá creciendo para mantener y adecuar las vías vehiculares. 
$\overline{30-\text { INDEC, Censo de Pobla- }}$ ción y Vivienda, 2010. do 634 habitantes por km², en el Departamento La Capital (cuya cabecera es la ciudad de Santa $\mathrm{Fe}$ ), se obtuvieron 170 habitantes por kilómetro cuadrado $^{30}$. Más allá de estar tomando como referencia unidades departamentales, las diferencias son notables, y es de suponer que las cabeceras brindan los datos más representativos del censo. Por lo tanto, la ocupación del área periférica sobre el valle de inundación no respondió a una saturación poblacional del centro, sino más bien a otras cuestiones, vinculadas con el modelo social del hiperconsumo, ya expuestas anteriormente. Y esta periferia, que se ocupó de manera dispersa, actualmente requiere consumos energéticos que podrían haberse evitado, aumentando la complejidad y la densidad en la ciudad consolidada. Puede decirse entonces que este despilfarro de suelo, de agua y de energía que la expansión urbana está provocando, y ya sin retorno, además del impacto ambiental por la obstrucción del reservorio fluvial tiene asimismo un impacto directamente sobre el gasto público, que irá gradualmente en ascenso con el fin de mantener una urbanización en un medio inestable e inadecuado para el establecimiento residencial.

Finalmente, es nuestra intención destacar que entre la urbanización y la naturaleza, así como entre la ciudad y el río, existe una amplia variedad de grises que consideramos urgente comenzar a vislumbrar. Ello será necesario si se quiere comenzar a realizar el pasaje desde un crecimiento urbano sostenido e insostenible ambientalmente (que ha sido la regla hasta ahora), hacia otra vía de conformación territorial que atienda al medio natural como parte del proceso antrópico, y esto sin duda tendrá su correlato en la ampliación de los derechos sociales a la práctica de los espacios y de la ciudad.

\section{BIBLIOGRAFÍA}

ASCHER, Francois (1995) Métapolis ou L'avenir des villes. Paris: Odile Jacob. BALLENT, Anahí (1998). "Country life: los nuevos paraísos, su historia y sus profetas"; en: revista Block n. ${ }^{\circ}$ 2. Revista de Cultura de la arquitectura, la ciudad y el territorio. Centro de Estudios de Arquitectura Contemporánea. Buenos Aires: Torcuato Di Tella; pp. 88-101. BAUMAN, Zygmunt (2007) Vida de consumo. Buenos Aires: Fondo de cultura Económica.

BENEVOLO, Leonardo (1967) Orígenes de la urbanística moderna. Tekné.

CARMAN, María (2011) Las trampas de la naturaleza. Medio ambiente y segregación en Buenos Aires. Buenos Aires: Fondo de Cultura Económica/CLACSO.

GRAVAGNUOLO, Benedetto (1998) Historia del Urbanismo en Europa 1750-1960. Madrid: Akal (1. ${ }^{\text {a }}$ edición de 1991). 
El paradigma del hiperconsumo en contextos espaciales ambientalmente críticos. Santa Fe (Argentina) y la urbanización del valle aluvial del río Paraná a finales del siglo xx

HALL, Peter (1996) Ciudades del mañana: historia del urbanismo en el siglo XX. Barcelona: del Serbal.

INDOVINA, Francesco (1990) La città difusa. Venecia: Daest.

LIPOVETSKY, Gilles (2007) La felicidad paradójica. Ensayo sobre la sociedad del hiperconsumo. Barcelona: Anagrama.

LIPOVETSKY, Gilles (2008). “El hiperconsumo en la era de la globalización”. Conferencia en Congreso Familias y Globalización ¿Qué globalización, para qué futuro? Disponible en: http://www.fad.es/sala_lectura/C2008-CONF_LIPOVETSKY.pdf

MONCLÚS, Francisco (1998) La ciudad Dispersa. Barcelona: Centre de Cultura Contemporània de Barcelona.

MUMFORD, Lewis (1996) La ciudad en la historia: sus orígenes, transformaciones y perspectivas. Buenos Aires: Infinito, vol. 2.

RÍOS, Diego y PÍREZ, Pedro (2008). “Urbanizaciones cerradas en áreas inundables del municipio de Tigre: ¿producción de espacio urbano de alta calidad ambiental?"; en: Eure; vol. XXXIV, n. ${ }^{\circ}$ 10. Santiago de Chile; pp. 99-119.

SVAMPA, Maristella (2001) Los que ganaron. La vida en los countries y barrios privados. Buenos Aires: Biblos.

SVAMPA, Maristella (2004) La brecha urbana. Countries y barrios privados. Buenos Aires: Capital Intelectual.

SICA, Paolo (1981) Historia del Urbanismo: el siglo XIX, T. 2. Madrid: Instituto de Estudios de Administración Local (1. 'a edición de 1980). 